\title{
Diagnostyka, profilaktyka i leczenie majaczenia po operacjach kardiochirurgicznych - doświadczenia własne
}

\author{
Diagnosis, prevention and treatment of delirium after cardiac surgery \\ - own experience
}

\author{
Michał Michniewicz ${ }^{1}$, Radosław Wilimski ${ }^{2}$, Piotr Hendzel ${ }^{2}$ \\ ${ }^{1}$ II Klinika Anestezjologii i Intensywnej Terapii Warszawskiego Uniwersytetu Medycznego \\ ${ }^{2}$ Klinika Kardiochirurgii I Katedry i Kliniki Kardiologii Warszawskiego Uniwersytetu Medycznego
}

\section{Streszczenie}

Zaburzenia poznawcze po operacjach kardiochirurgicznych są znaczącym problemem w opiece pooperacyjnej. Powodują wzrost występowania powikłań miejscowych i ogólnych, zwiększają śmiertelność oraz przedłużają okres hospitalizacji. W pracy przedstawiono postępowanie diagnostyczne, profilaktykę oraz leczenie majaczenia pooperacyjnego opracowane i stosowane na Oddziale Intensywnej Opieki Kardiochirurgicznej Kliniki Kardiochirurgii Warszawskiego Uniwersytetu Medycznego.

Słowa kluczowe: majaczenie pooperacyjne, profilaktyka, postępowanie kliniczne

Folia Cardiologica 2017; 12, 3: 328-332

\section{Wstęp}

Majaczenie jest istotnym problemem klinicznym u pacjentów po operacjach kardiochirurgicznych. Występuje u około $50 \%$ pacjentów [1, 2-6, 7]. Jest to jakościowe zaburzenie poznawcze cechujące się często pobudzeniem psychoruchowym mogące w skrajnych przypadkach prowadzić do stanu zagrożenia życia. Powoduje znaczący wzrost ryzyka powstania powikłań miejscowych (niestabilność mostka) z powodu pobudzenia ruchowego i nieprzestrzegania zaleceń, jak również zwiększenie ryzyka wystąpienia powikłań ogólnych, takich jak zakażenie, niewydolność nerek, niewydolność oddechowa i krążeniowa. Stan ten powoduje przedłużenie okresu hospitalizacji [7-13]. Śmiertelność po przebytym epizodzie majaczenia jest 2-krotnie większa $[13,14]$. Badania dotyczące profilaktyki majaczenia pooperacyjnego są nieliczne i ograniczone do małych populacji pacjentów. W związku z ryzykiem, jakie niesie za sobą wystąpienie majaczenia, uzasadniona jest próba opraco- wania skutecznego i prostego do stosowania schematu profilaktyki majaczenia.

Cel

Celem pracy jest przedstawienie własnych doświadczeń w diagnostyce, profilaktyce i leczeniu majaczenia po operacjach kardiochirurgicznych na podstawie aktualnych zaleceń i danych ze specjalistycznego piśmiennictwa.

\section{Definicja}

Zgodnie z 10. Międzynarodową Statystyczną Klasyfikacją Chorób i Problemów Zdrowotnych (ICD-10, International Statistical Classification of Diseases and Related Health Problems) kod F05 oznacza majaczenie niewywołane alkoholem ani innymi substancjami psychoaktywnymi. W 4. edycji Klasyfikacji Zaburzeń Psychicznych Amerykańskiego Towarzystwa Psychiatrycznego (DSM-IV, Diagnostic and Statistical Manual of Mental Disorders) występuje pod numerem 293.0 jako majaczenie wywołane przyczynami

Adres do korespondencji: lek. Michał Michniewicz, II Klinika Anestezjologii i Intensywnej Terapii, Warszawski Uniwersytet Medyczny,

ul. Banacha 1a, 02-097 Warszawa, e-mail: mmichniewicz@spcsk.pl 
ogólnoustrojowymi. Są to jakościowe, przemijające zaburzenia świadomości, nasilające się w godzinach nocnych [11, 12, 15-17]. U pacjentów występują omamy, zaburzenia pamięci, zaburzenia orientacji auto- i allopsychicznej, niepokój ruchowy, pobudzenie psychoruchowe, obserwuje się także formy hipoaktywne [13]. Jako jednostkę chorobową majaczenie sklasyfikowano w 1980 roku w 3. edycji Klasyfikacji Zaburzeń Psychicznych Amerykańskiego Towarzystwa Psychiatrycznego (DSM-III) $[12,18]$.

\section{Przyczyny majaczenia}

Majaczenie jest stanem o wieloczynnikowej, dokładnie niepoznanej etiologii i patofizjologii [12]. Prawdopodobnie występuje po nagłych zmianach utlenowania krwi i perfuzji narządowej oraz wahaniach jonowych i/lub metabolicznych w obrębie ośrodkowego układu nerwowego. Znane są czynniki ryzyka wystąpienia majaczenia [12].

Wśród czynników ryzyka związanych z operacjami kardiochirurgicznymi można wyróżnić czynniki przedoperacyjne (tab. 1) i śródoperacyjne (tab. 2) [4-6, 10, 13]. Postępowanie śród- i okołooperacyjne ma podstawowe znaczenie

Tabela 1. Przedoperacyjne czynniki ryzyka majaczenia po operacjach kardiochirurgicznych

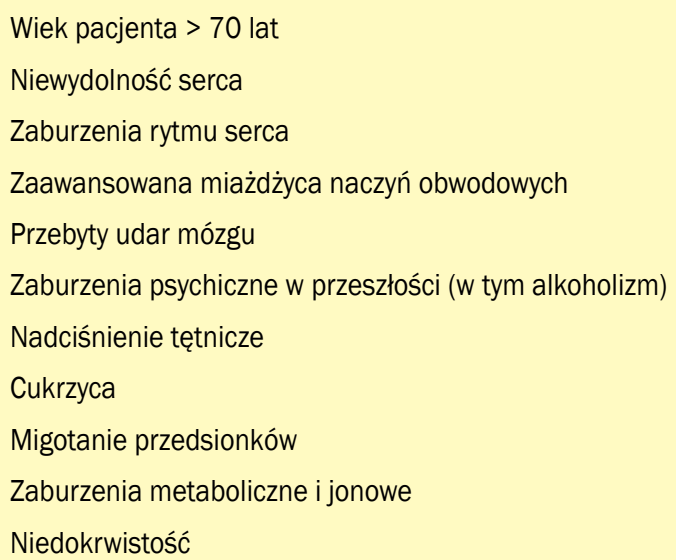

Przyjmowanie leków (beta-adrenalityki i adrenomimetyki, benzodiazepiny, opioidy, lidokaina)

Tabela 2. Środoperacyjne czynniki ryzyka majaczenia po operacjach kardiochirurgicznych

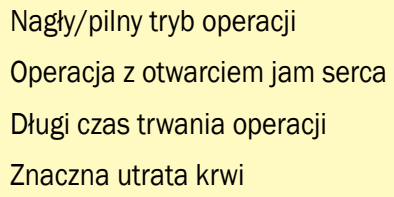

w zapobieganiu wystąpienia majaczenia, jednak wiele czynników ryzyka nie zależy od prowadzenia procesu leczenia.

\section{Metodologia}

\section{Ocena kliniczna}

Aby postawić diagnozę majaczenia, należy skorzystać z jednej z dostępnych skal oceny zaburzeń świadomości [ $[7,12$, 19]. Niedopuszczalna jest subiektywna ocena zachowania pacjenta, która może prowadzić do nierozpoznawania majaczenia, choć zdarzają się również przypadki jego zbyt częstego diagnozowania. Istnieje wiele skal oceny majaczenia [7, 13, 19]. (ocena zaburzeń świadomości [CAM, Confusion Assessment Method], Delirium Dedection Score [DDS], krótkie narzędzie przesiewowe do oceny otępień [MMSE, Mini-Mental State Examination), Intensive Care Delirium Screening Checklist [ICCDCS]). Z praktycznego punktu widzenia istotne jest stosowanie jednej skali na oddziale. Powinna ona być krótka, prosta, jednoznaczna, możliwa do przeprowadzenia u pacjenta po operacji kardiochirurgicznej i nie pozostawiać możliwości subiektywnej oceny.

\section{Profilaktyka}

Poza jakością opieki okołooperacyjnej oraz techniki operacyjnej rzadko dyskutowanym tematem jest znaczenie profilaktyki farmakologicznej w obniżaniu ryzyka wystąpienia majaczenia pooperacyjnego. Opublikowane informacje ograniczają się do zaleceń stosowania w krótkim czasie po operacji leków neurokognitywnych i neuroleptycznych [10]. Nie określono dokładnej listy leków, dawkowania ani czasu stosowania profilaktyki farmakologicznej występowania majaczenia.

\section{Leczenie}

Leczenie majaczenia jest trudne i trwa zazwyczaj kilka dni. Składa się z eliminacji potencjalnej przyczyny (jeśli jest rozpoznana), farmakoterapii, psychoterapii oraz unieruchomienia mechanicznego pacjenta $w$ razie potrzeby [12]. W farmakoterapii stosuje się przede wszystkim leki przeciwpsychotyczne. Lekiem pierwszego wyboru jest haloperidol, głównie ze względu na skuteczność i bezpieczeństwo terapii oraz możliwość podawania leku różnymi drogami (doustnie [p.o., per os], podjęzykowo (s.l., sub linquams), domięśniowo [i.m., intramuscular], dożylnie [i.v., intravenous]) $[12,13,20]$. W przypadku przeciwwskazań lub złej tolerancji haloperidolu stosuje się leki przeciwpsychotyczne II generacji, na przykład kwiatepinę czy risperidon [13]. Alternatywą w okresie silnego pobudzenia jest sedacja deksmedetomidyną. Należy pamiętać o stopniowym odstawianiu leczenia po ustąpieniu objawów majaczenia. Nagłe odstawienie może spowodować objawy odstawienne i wywołać nawrót majaczenia. Benzodiazepiny są wskazane w leczeniu wyłącznie majaczenia o podłożu alkoholowym [13]. Hydroksyzyna nie jest rekomendowana 
ze względu na komponentę cholinergiczną, która może nasilić jakościowe zaburzenia świadomości.

\section{Schemat postępowania profilaktyczno-} -terapeutycznego (doświadczenia własne) $\mathrm{Na}$ Oddziale Intensywnej Opieki Kardiochirurgicznej Kliniki Kardiochirurgii Warszawskiego Uniwersytetu Medycznego (WUM) opracowano schemat prewencji i leczenia majaczenia pooperacyjnego. Podstawą jest codzienna ocena pacjenta w skali oceny zaburzeń świadomości na oddziale intensywnej terapii (CAM-ICU, Confusion Assessment Method for the Intensive Care Unit), która, zdaniem autorów, jest najlepsza do praktycznego zastosowania, a według danych z piśmiennictwa cechuje ją największy stopień wiarygodności danych [7, 12, 13, 19, 21]. Pielęgniarki dokonują oceny każdego pacjenta w skali Oceny Stanu Świadomości (RASS, Richmond Agitation-Sedation Scale) co 2 godziny, co pozwala wcześnie wykryć potrzebę ponownej oceny stanu świadomości pacjenta przez lekarza. W momencie przyjęcia na oddział każdy pacjent jest analizowany pod kątem obecności czynników ryzyka wystąpienia majaczenia. Po spełnieniu kryteriów rozpoznania rozpoczyna się profilaktykę prowadzoną przez 2 doby. W kolejnych dobach dawki leków stosowanych profilaktycznie są stopniowo zmniejszane; często profilaktyka jest kontynuowana na oddziale zachowawczym. W przypadku wystąpienia majaczenia stosuje się 10-24-godzinny wlew deksmedetomidyny i równolegle haloperidol w dawkach frakcjonowanych, zazwyczaj p.o. lub s.l. W przypadku silnego pobudzenia psychoruchowego stosuje się w pierwszym okresie unieruchomienie mechaniczne i haloperidol i.v.

Postępowanie profilaktyczno-terapeutyczne na Oddziale Intensywnej Opieki Kardiochirurgicznej Kliniki Kardiochirurgii WUM obejmuje poniższe elementy:

- każdy pacjent jest oceniany minimum raz dziennie pod kątem majaczenia według algorytmu CAM-ICU;

- pacjentom w pierwszych dobach po operacji nie podaje się hydroksyzyny;

- u pacjentów obciążonych 3-5 czynnikami ryzyka wdraża się profilaktykę majaczenia (haloperidol p.o. 0,5 mg rano, 0,5 $\mathrm{mg}$ w południe, $1 \mathrm{mg}$ wieczorem), jeśli nie ma przeciwwskazań. Pierwsza dawka jest podawana 6-18 h od przyjęcia na oddział intensywnej terapii kardiologicznej (OITK). Farmakoterapię kontynuuje się do wypisania z OITK, nie dłużej jednak niż przez 2 doby;

- u pacjentów obciążonych 5 lub większą liczbą czynników ryzyka wdraża się prewencję majaczenia (deksmedetomidyna) we wlew i.v. 0,2-0,3 $\mu \mathrm{g} / \mathrm{kg} \mathrm{mc} . / \mathrm{h}$ przez 10-20 h), jeśli nie ma przeciwwskazań. Początek wlewu następuje 30 minut przed ekstubacją. Równolegle jest prowadzona profilaktyka (patrz pkt. 3);

- w przypadku wystąpienia majaczenia stosuje się 24-godzinny wlew deksmedetomidyny i.v. w dawce 0,2-
-0,7 $\mu \mathrm{g} / \mathrm{kg} \mathrm{mc} / \mathrm{h}$ (jeśli nie ma przeciwwskazań) oraz haloperidol p.o./i.v. W przypadku braku skuteczności leczenia dodatkowo podaje się inne leki - zależnie od stanu pacjenta;

- w przypadku utrzymywania się majaczenia po 24-godzinnym postępowaniu, jak w punkcie 4, konieczna jest konsultacja psychiatryczna.

Czynniki ryzyka majaczenia uwzględniane w schemacie są następujące:

- zaawansowany wiek (> 70. rż.);

- choroba niedokrwienna serca z frakcją wyrzutową (EF, ejection fraction) poniżej 30\%;

- zaawansowana miażdżyca naczyń obwodowych;

- przebyty udar mózgu;

- migotanie przedsionków;

- nadciśnienie tętnicze;

- cukrzyca;

- występowanie zaburzeń psychicznych w przeszłości;

- nagły tryb operacji;

- operacja z otwarciem jam serca;

- znaczna utrata krwi (konieczność transfuzji śród- lub pooperacyjnej);

- długi czas trwania operacji (> $6 \mathrm{~h}$ );

- spadek prężności tlenu we krwi w trakcie operacji $\left(\mathrm{pO}_{2}<60 \mathrm{~mm} \mathrm{Hg}\right)$;

- konieczność wspomagania hemodynamicznego (katecholaminami lub kontrapulsacją wewnątrzaortalną).

\section{Wstępna ocena wyników klinicznych wprowadzonego schematu profilaktyki majaczenia}

Przed wprowadzeniem aktualnie stosowanego schematu postępowania odsetek pacjentów z rozpoznanym majaczeniem w okresie okołooperacyjnym wynosił około 30\%. Dane uzyskano retrospektywnie z raportów lekarskich i pielęgniarskich. Nie stosowano wówczas ujednoliconej skali oceny, a kliniczne rozpoznanie majaczenia polegało na subiektywnej ocenie braku logiki w wypowiedziach pacjenta, charakterystycznego zachowania oraz najczęściej pobudzenia psychoruchowego. Prawdopodobnie liczba pacjentów z majaczeniem jest niedoszacowana, głównie z powodu braku danych o skąpoobjawowej formie tego zespołu zaburzeń. Z tego względu w niniejszym artykule nie przeprowadzono porównawczej analizy statystycznej z wykorzystaniem niepełnych danych zebranych retrospektywnie. W związku z powyższym przedstawiane wyniki mają charakter opisowy.

Po wprowadzeniu w klinice schematu profilaktyki majaczenia prospektywną obserwacją, trwającą od 1 lipca 2016 roku do 31 grudnia 2016 roku, objęto 150 pacjentów. Majaczenie wczesne (rozpoznane w okresie 48 h po operacji) wystąpiło u 7,2\% pacjentów, majaczenie późne (rozpoznane > 48 h po operacji) u 10,1\% pacjentów. 
Tabela 1. Częstość występowania majaczenia przed wprowadzeniem profilaktyki

$\begin{array}{lcccccccccc}\text { Liczba czynników ryzyka } & 0 & 1 & 2 & 3 & 4 & 5 & 6 & 7 & 8 & 9 \\ \text { Pacjenci (\%) } & 4 & 17 & 28 & 19 & 14 & 11 & 3 & 2 & 1 & 1 \\ \text { Majaczenie wczesne (\%) } & 0 & 0 & 10 & 21 & 23 & 25 & 32 & 37 & 42 & 80 \\ \text { Majaczenie późne (\%) } & 0 & 0 & 12 & 17 & 29 & 35 & 43 & 6 & 0 & 0\end{array}$

Tabela 2. Częstość występowania majaczenia po wprowadzeniu profilaktyki

$\begin{array}{lcccccccccc}\text { Liczba czynników ryzyka } & 0 & 1 & 2 & 3 & 4 & 5 & 6 & 7 & 8 & 9 \\ \text { Pacjenci (\%) } & 4 & 19 & 27 & 17 & 16 & 10 & 3 & 2 & 1 & 1 \\ \text { Majaczenie wczesne (\%) } & 0 & 0 & 5,4 & 16,7 & 4,6 & 23,1 & 0 & 0 & 0 & 0 \\ \text { Majaczenie późne (\%) } & 0 & 0 & 8,1 & 12,5 & 18,2 & 30,8 & 0 & 0 & 0 & 0\end{array}$

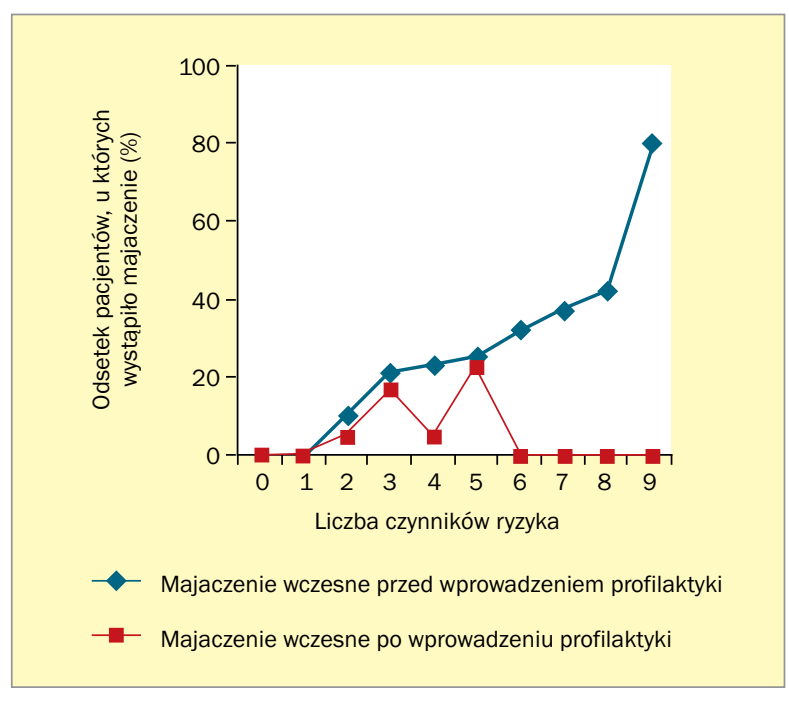

Rycina 1. Częstość występowanie majaczenia wczesnego

Przed wprowadzeniem schematu profilaktyki orientacyjna częstość majaczenia była wprost proporcjonalna do liczby czynników ryzyka. U pacjentów obciążonych 7 lub większą liczbą czynników ryzyka nie obserwowano majaczenia późnego, jednak u większości z nich wystąpiło majaczenie wczesne, utrzymujące się kilka dni.

Po wprowadzeniu schematu zaobserwowano, że majaczenie nie występuje u pacjentów cechujących się nie więcej niż jednym czynnikiem ryzyka. U pacjentów obciążonych wyższym ryzykiem, u których zastosowano profilaktycznie deksmedetomidynę, majaczenia nie obserwowano. $\mathrm{Na}$ podstawie powyższych obserwacji schemat postępowania został zmodyfikowany. Obecnie profilaktyczne stosowanie haloperidolu zaleca się u pacjentów obciążonych 2-4 czynnikami ryzyka, przez minimum 3 doby. Deksmedetomidynę stosuje się profilaktycznie u pacjentów obciążonych 5 lub większą liczbą czynników ryzyka.

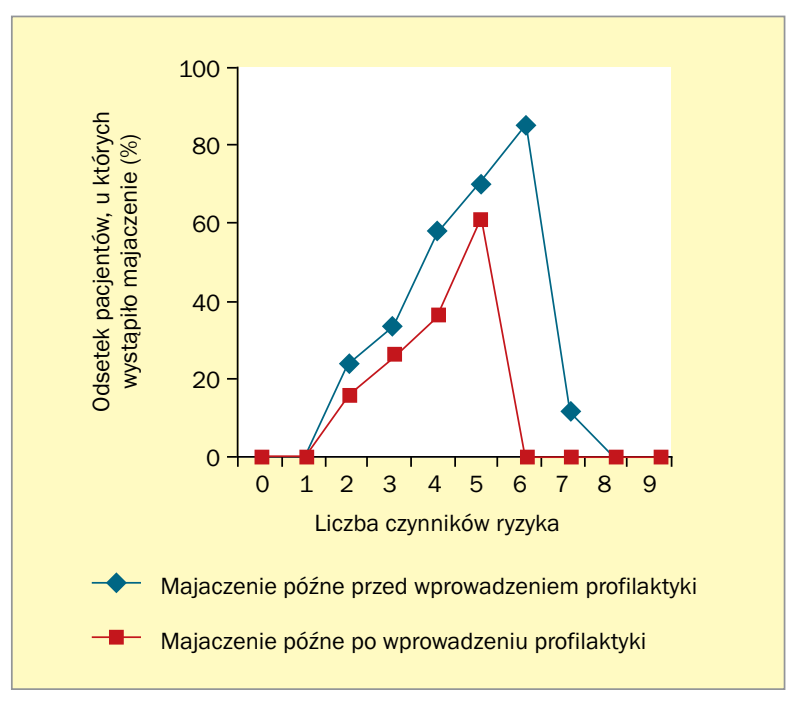

Rycina 2. Częstość występowanie majaczenia późnego

Częstość występowania majaczenia wczesnego przed wprowadzeniem profilaktyki i po jej wprowadzeniu przedstawiono w tabelach 1 i 2 oraz rycinach 1 i 2.

\section{Wnioski i podsumowanie}

Identyfikacja pacjentów zagrożonych wystąpieniem majaczenia i zastosowanie wobec nich profilaktyki farmakologicznej może być skuteczną metodą ograniczenia liczby epizodów majaczenia po operacjach kardiochirurgicznych [12]. Regularna ocena stanu świadomości pacjenta i wczesne wdrożenie leczenia potencjalnie wpływa na zmniejszenie liczby powikłań i śmiertelności po operacjach kardiochirurgicznych. Zastosowana strategia diagnostyki, profilaktyki i leczenia przedstawiona w niniejszej pracy i stosowana na Oddziale Intensywnej Opieki Kardiochirurgicznej Kliniki Kardiochirurgii WUM okazała się skuteczna w codziennej 
praktyce leczenia pacjentów po operacjach kardiochirurgicznych i znacząco zmniejszyła częstość występowania majaczenia w okresie pooperacyjnym. Wyniki wymagaja jednak dokładnej analizy statystycznej. Obecnie jest analizowany wpływ poszczególnych czynników ryzyka na częstość rozpoznania majaczenia po operacjach kardiochirurgicznych. Ze względu na skuteczność kliniczną proponowanego postępowania profilaktyczno-terapeutycznego badania z udziałem grupy kontrolnej otrzymującej placebo wydają się nieuzasadnione.

\section{Abstract}

Delirium after cardiac surgery is a major problem in a postoperative care period. It results in significant short- and long-term morbidity and mortality and prolongs in-hospital stay. The paper presents tools to assist in diagnosing, preventing and treating postoperative delirium, developed and used in Intensive Care Unit at Cardiac Surgery Department of Medical University of Warsaw.

Key words: postoperative delirium, prevention, clinical management

Folia Cardiologica 2017; 12, 3: 328-332

\section{Piśmiennictwo}

1. Kazimierski J. Pooperacyjne zaburzenia świadomości - praktyczny przewodnik interdyscyplinarny Continuo, Wrocław 2014.

2. Gao L, Taha R, Gauvin D, et al. Postoperative cognitive dysfunction after cardiac surgery. Chest. 2005; 128(5): 3664-3670, doi: 10.1378/ /chest.128.5.3664, indexed in Pubmed: 16304328.

3. Fricchione GL, Nejad SH, Esses JA, et al. Postoperative delirium. Am J Psychiatry. 2008; 165(7): 803-812, doi: 10.1176/appi.ajp.2008. 08020181, indexed in Pubmed: 18593786.

4. Kazmierski J, Kowman M, Banach M, et al. Preoperative predictors of delirium after cardiac surgery: a preliminary study. Gen Hosp Psychiatry. 2006; 28(6): 536-538, doi: 10.1016/j.genhosppsych. 2006.08.007, indexed in Pubmed: 17088170.

5. Saniova B, Drobny M, Sulaj M. Delirium and postoperative cognitive dysfunction after general anesthesia. Med Sci Monit. 2009; 15(5): CS81-CS87, indexed in Pubmed: 19396043.

6. Bucerius J, Gummert JF, Borger MA, et al. Predictors of delirium after cardiac surgery delirium: effect of beating-heart (off-pump) surgery. J Thorac Cardiovasc Surg. 2004; 127(1): 57-64, doi: 10.1016/ /S0022, indexed in Pubmed: 14752413.

7. Świerzy KA, Pudlo R, Wesołowski B, et al. The Polish language version of the Confusion Assessment Method - a questionnaire for the screening of consciousness disorders. Kardiochir Torakochirurgia Pol. 2016; 13(2): 178-184, doi: 10.5114/kitp.2016.61060, indexed in Pubmed: 27516799.

8. Ozyurtkan MO, Yildizeli B, Kuşçu K, et al. Postoperative psychiatric disorders in general thoracic surgery: incidence, risk factors and outcomes. Eur J Cardiothorac Surg. 2010; 37(5): 1152-1157, doi: 10.1016/j.ejcts.2009.11.047, indexed in Pubmed: 20117012.

9. Rosen SF, Clagett GP, Valentine RJ, et al. Transient advanced mental impairment: an underappreciated morbidity after aortic surgery. J Vasc Surg. 2002; 35(2): 376-381, indexed in Pubmed: 11854738.
10. Krzych $\measuredangle$, Święch W, Białek K, et al. Majaczenie u chorych kardiochirurgicznych - problem wielodyscyplinarny. Kardiola Pol 2011; 69. 2011; 69(5): 479-481.

11. van ZyI LT, Seitz DP. Delirium concisely: condition is associated with increased morbidity, mortality, and length of hospitalization. Geriatrics. 2006; 61(3): 18-21, indexed in Pubmed: 16522131.

12. Klich-Rączka A, Piotrowicz K, Grodzicki T. Majaczenie w świetle najnowszych zaleceń. Przegl Lek. 2009; 66: 4.

13. Rymaszewska J. Zaburzenia świadomości - problem lekarza na dyżurze. Psychiatr Prakt Klin. 2008; 1(1): 22-29.

14. Lipowski ZJ. Delirium: acute confusional states. Oxford University Press, Oxford 1990.

15. Bilikiewicz A. Psychiatria. PZWL, Warszawa 2001.

16. Bilikiewicz A, Puzyński S, Rybakowski J, Wciórka J. Psychiatria. Urban \& Partner, Wrocław 2002.

17. Szczudlik A, Liberski PP, Barcikowska M. Otępienie. Wydawnictwo UJ, Kraków 2004.

18. de Rooij SE, Schuurmans MJ, van der Mast RC, et al. Clinical subtypes of delirium and their relevance for daily clinical practice: a systematic review. Int J Geriatr Psychiatry. 2005; 20(7): 609-615, doi: 10.1002/ /gps.1343, indexed in Pubmed: 16021665.

19. Luetz A, Heymann A, Radtke FM, et al. Different assessment tools for intensive care unit delirium: which score to use? Crit Care Med. 2010; 38(2): 409-418, doi: 10.1097/CCM.0b013e3181cabb42, indexed in Pubmed: 20029345.

20. Michuald L, Bula C, Berney A. Delirium guidelines for general hospitals. J Psych Res. 2007; 62: 371.

21. Inouye S. Clarifying confusion: the confusion assessment method. Ann Inter Med. 1990; 113(12): 941-948, doi: 10.7326/0003-4819113-12-941. 